\title{
Fetal and life course origins of serum lipids in mid-adulthood: results from a prospective cohort study
}

Per E Gustafsson ${ }^{1 *}$, Urban Janlert ${ }^{2}$, Töres Theorell ${ }^{3}$, Hugo Westerlund ${ }^{3}$, Anne Hammarström $^{1}$

\begin{abstract}
Background: During the past two decades, the hypothesis of fetal origins of adult disease has received considerable attention. However, critique has also been raised regarding the failure to take the explanatory role of accumulation of other exposures into consideration, despite the wealth of evidence that social circumstances during the life course impact on health in adulthood. The aim of the present prospective cohort study was to examine the contributions of birth weight and life course exposures (cumulative socioeconomic disadvantage and adversity) to dyslipidemia and serum lipids in mid-adulthood.

Methods: A cohort (effective $n=824,77 \%$ ) was prospectively examined with respect to self-reported socioeconomic status as well as stressors (e.g., financial strain, low decision latitude, separation, death or illness of a close one, unemployment) at the ages of 16, 21, 30 and 43 years; summarized in cumulative socioeconomic disadvantage and cumulative adversity. Information on birth weight was collected from birth records. Participants were assessed for serum lipids (total cholesterol, low- and high-density lipoprotein cholesterol and triglycerides), apolipoproteins (A1 and B) and height and weight (for the calculation of body mass index, BMI) at age 43. Current health behavior (alcohol consumption, smoking and snuff use) was reported at age 43 .

Results: Cumulative life course exposures were related to several outcomes; mainly explained by cumulative socioeconomic disadvantage in the total sample (independently of current health behaviors but attenuated by current BMI) and also by cumulative adversity in women (partly explained by current health behavior but not by BMI). Birth weight was related only to triglycerides in women, independently of life course exposures, health behaviors and BMI. No significant association of either exposure was observed in men.
\end{abstract}

Conclusions: Social circumstances during the life course seem to be of greater importance than birth weight for dyslipidemia and serum lipid levels in adulthood.

\section{Background}

Since the early $1990 \mathrm{~s}$, the research field of life course epidemiology has studied the health effects of biological and social exposures during different periods of life and the corresponding long-term processes spanning over the life course [1]. One line of research focuses on fetal origins of disease, with one hypothesis stating that suboptimal metabolic conditions during fetal life, e.g. indicated by lower birth weight, increase the risk for cardiovascular disease in adulthood [2]. Low birth

\footnotetext{
* Correspondence: Per.E.Gustafsson@fammed.umu.se

'Dept of Public Health and Clinical Medicine, Family Medicine, Umeå

University, Umeå, Sweden

Full list of author information is available at the end of the article
}

weight has been shown to be associated with cardiovascular mortality $[3,4]$ and to predict a number of related disorders, such as hypertension, obesity and insulin resistance [5-7]. The fetal origins hypothesis has, however, been criticized for overestimation of effects [8] and failure to consider the wealth of other exposures between birth and adulthood. One of the challenges of studying the fetal origins hypothesis is how to incorporate confounding and explanatory effects of accumulated stress over the life span into the analyses [9], which is a manifest limitation of past and present research on the field. The present study will address this issue by examining the importance of birth weight as well as social 
exposures during the life course, for dyslipidemia and serum lipid levels in mid-adulthood.

Early studies on the fetal origins of serum lipids and dyslipidemia indicated that lower birth weight was linked to an atherogenic lipid profile in adulthood [10-12]. However, subsequent studies have only provided weak support for birth weight as a determinant of adult lipid levels $[13,14]$. The association between birth weight and adult total cholesterol (TC) levels appear to be too small to be of clinical significance, as concluded in a literature review by Huxley et al [14]. Regarding the apolipoproteins (Apo) A1 and B, a few studies report Apo $\mathrm{B}$ to be elevated among those born small $[10,15,16]$. For low-density and high-density lipoprotein cholesterol (LDL-C and HDL-C, respectively), findings are inconsistent not only regarding the strength but also regarding the direction of the association, as pointed out in a review by Lauren et al [13]. Triglycerides might be the lipid providing the most consistent support the fetal origins hypothesis [13]. More recent studies report weak relationships between birth weight and adult lipid levels $[16,17]$.

In conclusion, birth weight might only be weakly related to adult serum lipids. This has been interpreted as an argument for lifestyle during adulthood as a major determinant of atherogenic serum lipids [14]. Alternatively, weak associations between birth weight and lipids could be interpreted as an argument in favor of social pathways to cardiovascular risk, which may or may not operate through behavioral pathways. Indeed, there is an increasing awareness that the accumulation of social exposures over the life course, e.g. socioeconomic status [18] and social adversity such as inadequate housing conditions [19], economic hardship [20] and adverse childhood events [21], matters for cardiovascular health in adulthood. Social exposures in both childhood and adulthood have been shown to be related to adult lipid levels $[22,23]$. Some studies indicate that serum lipids are related to social life course exposures only in women [24], and to birth weight only in men [25]. Alas, the accumulation of social exposures over the life course has scarcely been studied in conjunction with birth weight, despite the explanatory or confounding role such factors might play [9]. In fact, only a minority of studies on birth weight and blood lipids have adjusted for current socioeconomic status [13], which is a substantial weakness of previous research. Delineating the relative importance of fetal and later exposures for lipid status in adulthood is necessary for public health interventions and policies directed at cardiovascular risk. The present cohort study seeks to contribute to this task, by combining data on birth weight, prospectively collected exposures on socioeconomic and other adverse social exposures from adolescence to adulthood, and measurement of serum lipid levels at 43 years of age. The aims are to examine the relative contributions of birth weight and accumulated social life course exposures to dyslipidemia and serum lipid levels in midadulthood.

\section{Methods}

\section{Participants and procedures}

The sample was based on the Northern Swedish Cohort, a 27-year prospective cohort study comprising all pupils in the ninth grade of the Swedish compulsory school living in Luleå in 1981, when the participants where 16 years of age ( $\mathrm{N}=1083 ; 506$ girls and 577 boys). Followup surveys were conducted when the participants were 18 (1983), 21 (1986), 30 (1995) and 43 (2008) years of age. In this report, data from the 1981, 1986, 1995 and 2008 surveys are presented. The cohort has in various comparisons been found to be representative of the Swedish population [26]. Of the original cohort, there were 1071 subjects still alive in 2008, of which 1003 (93.7\%) agreed to participate in the survey at age 43. Due to non-response on one or more key measures (see below), the effective sample size of the present report is $\mathrm{n}=824$ (77\%). All participants provided informed consent at all surveys and the study was approved by the Regional Ethical Review Boards in Umeå. For more details about the study, see Hammarström [26] and Hammarström \& Janlert [27].

Participants completed a comprehensive questionnaire at all follow-ups. Although the composition of the questionnaire varied at different ages due to the age-specific relevance of some topics, the main areas covered in all versions included health and health behaviors, social and socioeconomic conditions, school/working conditions and leisure activities. The majority of items originated from the Swedish Survey of Living Conditions [28] and the Low-Income Study [29]. In 2008, blood samples were collected during a health examination.

\section{Measures}

\section{Exposure: body size at birth}

Delivery records of the participants' mothers from 1965 (i.e., pertaining to the participants' own birth) were retrieved from the archives of the respective delivery ward. From the delivery records, information on birth weight, length, date of delivery, date for last menstruation prior to delivery, and diagnoses according to the Swedish adaptation of the 6th revision of the International Classification of Disease [30], was documented.

Birth weight $(B W)(\mathrm{kg})$, Birth length $(\mathrm{cm})$, and ponderal index (weight/length ${ }^{3}, \mathrm{~kg} / \mathrm{m} 3$ ) were initially used as the main continuous measures of body size at birth. Since both ponderal index and birth length were less consistently related to lipid levels than was BW in 
preliminary analyses, these alternative measures were excluded from further analyses. Preterm or premature birth (defined as either a diagnosis of immaturity or birth < week 37 , or if missing record data proxied as birth weight $<2500 \mathrm{~g}$ ) did not influence the estimated associations, why all cases were included in the analyses. The associations between birth weight and lipids appeared to be approximately rectilinear by graphical inspection.

\section{Exposure: cumulative adversity over the life course}

Adversity was defined as potentially stressful environmental exposures. Items representing this concept were selected from the questionnaires at each age, while items substantially dependent on subjective appraisal of the exposure were not selected. Since different versions of the questionnaire were used at different ages, the set of adversity components also varied between measurements. All non-binary components were dichotomized as close to the 80th percentile as possible. All components were then added generating an index of cumulative adversity. The following components of adversity were included $(\mathrm{k}=28)$ :

Parental illness (age 16) was defined as one or both parents having a physical illness, mental problems, and/or alcohol or drug problems, as reported by the adolescent.

Parental loss (age 16) was defined as either having experienced parental separation/divorce $(n=181)$, or parents never living together $(n=17)$, or death of either parent $(\mathrm{n}=28)$.

Parental unemployment (age 16) was defined as one or both parents being unemployed or granted a disability pension at the time of the survey (housewives were classified as employed).

Residential crowding (age 16) was defined as the participant not having her/his own room.

Residential mobility (age 16 and 21). The participants were asked how many times they had moved in their lifetime (at age 16) and during the last three years (at age 21). High residential mobility was defined as $>2$ moves $(=1)$, compared to $0-2$ moves $(=0)$ at each time period.

Unemployment (age 21, 30 and 43) was defined as current own unemployment or disability pension, based on a question about current labor market situation.

Spousal unemployment (age 30 and 43). The participants were asked if their partner had been unemployed during the last five years (age 30), and about the partner's current labor market situation (age 43). In the latter case, unemployment or disability pension was considered unemployment.

Low cash margin (age 21, 30 and 43). The participants were asked if it would be possible for them to raise a certain amount of cash within a week [31]. The amount was 5,000SEK at age $21,13,000$ SEK at age 30 , and 15,000 SEK at age 43.

Low income (age 21) was defined as a self-reported monthly income $<3,400$ SEK.

Financial strain (age 30 and 43). The participants were asked how often they were forced, due to financial reasons, to abstain from any out of eleven different material needs (eat a cooked meal; buy clothes; pay the rent or other invoices; go to the movies, concert, theatre; invite relatives or friends; buy presents; go away on vacation; subscribe to a magazine; spare time activities or hobbies; go to a restaurant or pub). The response options were 'often', 'seldom', 'never' or 'not applicable'. The number of 'often' responses was added up to an index and dichotomized at the $80^{\text {th }}$ percentile, resulting in 3 or more frequent cut-backs considered as high financial strain at age 30 , and one or more at age 43.

Illness and death of close ones (age 21, 30 and 43). The participants were asked if someone close had had a serious or long-term illness, and if someone close had died, during the last three years (age 21), 12 months (age 30), or five years (age 43). A positive response was considered an adversity, separately for illness and death.

Separation (age 30 and 43) was defined as having broken up from a long-term relationship involving co-habituation during the last 12 months (at age 30 ) or since the age of 30 (at age 43).

Bullying or sexual harassment at work (age 30 and 43). The participants were asked how often they had been exposed to personal persecution at the workplace through mean words and actions from bosses or colleagues, or exposed to sexual harassment through unwelcome or degrading sexual insinuations. Due to the low frequencies, a couple of days per months of either bullying or sexual harassment was considered exposure $(=1)$.

Exposure to threat and violence (age 30 and 43). The participants were asked if they had been exposed to threats of violence that were so serious that she or he was scared, and if they had been exposed to physical violence, during the last 12 months. Due to low frequencies, a positive response on either violence or threat was considered exposure $(=1)$.

Social isolation (age 30 and 43). The participants responded to four questions from the Availability of Social Integration (AVSI) scale [32,33], concerning the number of people available for emotional and social support. A total score of $<80^{\text {th }}$ percentile was regarded as exposure to social isolation.

Low decision latitude (age 30 and 43). Participants responded to 6 items about decision latitude from the Swedish Demand-Control Questionnaire (DCQ) [34], with responses on a four-level Likert scale, which were added together. The group belonging to the $20^{\text {th }}$ percentile was considered exposed to low decision latitude. 


\section{Exposure: cumulative socioeconomic disadvantage over the life course}

Participants' own occupation at age 21, 30 and 43 were coded according to the socioeconomic classification system of Statistics Sweden [35]. The classification is based on the main divisions of manual workers, non-manual employees and self-employed. Manual workers were categorized as low SES (=1) while non-manual employees and self-employed were categorized as high SES (= $0)$. For participants who were not currently working and for whom information on previous occupation was not available (only at age 21 and 30), e.g. for participants who were unemployed, studying or doing military service, the highest educational attainment was used as a proxy ( $n=206$ for SES at age 21, $n=41$ for SES at age 30): university-preparatory high school or university studies indicated high SES (=0) while other types of high school education or lower were classified as low SES (= 1 ). At age 16, parental occupation was coded into three social groups. Having both parents in 'social group 3', comparable to manual workers, defined low SES (= 1), while having at least one parent in social group 1 or 2 defined high SES $(=0)$.

Cumulative socioeconomic disadvantage was operationalized as the number of life course periods with low SES (range 0-4).

\section{Current health behavior and body size at age $\mathbf{4 3}$}

Self-reported health behavior at age 43 was examined as potential confounders: daily smoking (yes/no), daily snuff use (yes/no), alcohol consumption. Alcohol consumption (average gram pure alcohol consumption per week) was estimated from questions on the frequency of alcoholic beverage consumption, and approximate volume of beverage per occasion (separate items for beer, wine and spirits) and dichotomized at $110 \mathrm{~g} /$ week for men and $80 \mathrm{~g} /$ week for women [36]. At age 43, weight and height was measured according to the MONICA manual [37] as a part of a health examination at the participant's respective health care center. From this information BMI $\left(\mathrm{kg} / \mathrm{m}^{2}\right)$ was calculated. For those who had not completed weight and height measurement $(\mathrm{n}=9)$, BMI calculations were based on self-reported height/weight. There was a high correspondence between measured and self-reported height, $\mathrm{r}(891)=.91$.

\section{Outcome: blood lipids at age 43}

At age 43, participants were invited to a health examination at their local health care center, including blood sampling after an overnight fast. Samples were assessed with respect to total cholesterol (TC), low-density lipoprotein cholesterol (LDL-C), high-density lipoprotein cholesterol (HDL-C), triglycerides (TG) Apolipoprotein (Apo) A1 and Apo B (for brevity, all outcomes including apolipoproteins are collectively referred to as 'lipids' in the text), according to the routine methods at the Department of Clinical Chemistry, Umeå University Hospital, Sweden. TG concentrations were logarithmically transformed by the natural logarithm prior to analysis to achieve a normal distribution. The other outcomes displayed approximately normal distributions.

Dyslipidemia was defined according to the 2003 European Society of Hypertension-European Society of Cardiology guidelines [38]: total cholesterol $>6.5 \mathrm{mmol} / \mathrm{L}$, or LDL cholesterol $>4.0 \mathrm{mmol} / \mathrm{L}$, or HDL cholesterol $<1.2 \mathrm{mmol} / \mathrm{L}$ for women and $<1.0 \mathrm{mmol} / \mathrm{L}$ for men. This definition was used as a measure of high-risk dyslipidemia, rather than more recent guidelines which include individuals of lower risk [39] (in the present sample $71.5 \%$ were classified as having dyslipidemia according to the more recent criteria). Participants with medication against dyslipidemia $(n=28)$ were also classified as having dyslipidemia.

\section{Data analysis}

There were 1003 participants in the study of which 888 had at least one valid lipid measure. Of these $n=840$ had all six measures available as well as information on birth weight and life course exposures, comprising our effective sample. Due to missing data on either birth weight or questionnaires, the effective $n$ went down to $n$ $=824$ (396 women, 428 men) when all variables were entered into the analysis ( $77 \%$ of the original cohort still alive). See Table 1 for descriptive statistics.

Those with missing lipid data $(n=115)$ did not differ significantly from those with available lipid data $(\mathrm{n}=$ 888) regarding birth weight (t test; $\mathrm{p}=.09 ; \mathrm{M}=3.48$ and $3.38 \mathrm{~kg}$, respectively), cumulative adversity $(\mathrm{p}=.16)$ or cumulative SES $(p=.60)$. Those with dyslipidemia medication $(n=28)$ did not differ from those without medication regarding SES, adversity or birth weight (all ps $>.10$ ), and where therefore included in the analyses.

Since different life course models might be relevant to explain socioeconomic influences on health, we employed a formal method recently proposed by Mishra et al. [40] for comparing the fit of different life course models. The method is based on a partial F test of a saturated model including all possible parameters (including interactions), and a reduced nested model where restrictions have been imposed on the saturated model to correspond to a specific life course model [40]. In our case we tested the cumulative risk and the early critical period models for the different lipid outcomes in sex-stratified analyses. In these analyses, all F-statistics were non-significant $(F(14,380-412)<1.52)$ for both the cumulative risk and the critical period model (data not shown), indicating that the restriction of either model did not confer any significant reduction in model fit. 
Table 1 Descriptive statistics of the main variables in women, men and in the total sample

\begin{tabular}{|c|c|c|c|c|c|c|c|}
\hline \multirow[t]{2}{*}{ Variable } & \multicolumn{2}{|c|}{ Women } & \multicolumn{2}{|l|}{ Men } & \multicolumn{3}{|c|}{ Total sample } \\
\hline & Estimate & $\mathbf{N}$ & Estimate & $\mathbf{N}$ & Estimate & $\mathbf{N}$ & $\begin{array}{c}\text { P } \\
\text { value }^{1}\end{array}$ \\
\hline \multicolumn{8}{|l|}{ Exposures } \\
\hline $\begin{array}{l}\text { Birth weight } \\
(\mathrm{kg})\end{array}$ & $\begin{array}{c}3.30 \\
(0.53)\end{array}$ & 473 & $\begin{array}{c}3.47 \\
(0.60)\end{array}$ & 517 & $\begin{array}{c}3.39 \\
(0.57)\end{array}$ & 990 & $<.001$ \\
\hline $\begin{array}{l}\text { Cumulative } \\
\text { low SES }\end{array}$ & $\begin{array}{c}1.64 \\
(1.32)\end{array}$ & 461 & $\begin{array}{c}1.91 \\
(1.41)\end{array}$ & 503 & $\begin{array}{c}1.78 \\
(1.38)\end{array}$ & 964 & .003 \\
\hline $\begin{array}{l}\text { Cumulative } \\
\text { adversity }\end{array}$ & $\begin{array}{c}6.52 \\
(3.50)\end{array}$ & 482 & $\begin{array}{l}5.65 \\
(3.14)\end{array}$ & 521 & $\begin{array}{c}6.07 \\
(3.34)\end{array}$ & 1003 & $<.001$ \\
\hline $\begin{array}{l}\text { High alcohol, } \\
\mathrm{n}(\%)\end{array}$ & $38(8.0)$ & 477 & 64 (12.5) & 510 & $\begin{array}{c}102 \\
(10.3)\end{array}$ & 987 & .018 \\
\hline $\begin{array}{l}\text { Smoking, n } \\
(\%)\end{array}$ & $\begin{array}{c}113 \\
(23.7) \\
\end{array}$ & 477 & $90(17.7)$ & 508 & $\begin{array}{c}203 \\
(20.6)\end{array}$ & 985 & .021 \\
\hline $\begin{array}{l}\text { Snuff use, n } \\
(\%)\end{array}$ & $62(13.0)$ & 478 & $\begin{array}{c}156 \\
(31.1) \\
\end{array}$ & 502 & $\begin{array}{c}218 \\
(22.2)\end{array}$ & 980 & $<.001$ \\
\hline \multicolumn{8}{|l|}{ Outcomes } \\
\hline $\begin{array}{l}\text { Dyslipidemia, } \\
\mathrm{n}(\%)\end{array}$ & $\begin{array}{c}143 \\
(33.7)\end{array}$ & 424 & $\begin{array}{c}212 \\
(46.7)\end{array}$ & 454 & $\begin{array}{c}355 \\
(40.4)\end{array}$ & 878 & $<.001$ \\
\hline $\begin{array}{l}\text { Total } \\
\text { cholesterol }\end{array}$ & $\begin{array}{l}5.21 \\
(0.93)\end{array}$ & 424 & $\begin{array}{l}5.50 \\
(0.99)\end{array}$ & 462 & $\begin{array}{c}5.36 \\
(0.98)\end{array}$ & 886 & $<.001$ \\
\hline Triglycerides $^{2}$ & $\begin{array}{c}1.07 \\
(0.61) \\
\end{array}$ & 423 & $\begin{array}{c}1.71 \\
(1.28) \\
\end{array}$ & 455 & $\begin{array}{c}1.40 \\
(1.06) \\
\end{array}$ & 878 & $<.001$ \\
\hline $\begin{array}{l}\mathrm{HDL} \\
\text { cholesterol }\end{array}$ & $\begin{array}{c}1.52 \\
(0.37) \\
\end{array}$ & 422 & $\begin{array}{c}1.20 \\
(0.32) \\
\end{array}$ & 453 & $\begin{array}{c}1.35 \\
(0.38) \\
\end{array}$ & 875 & $<.001$ \\
\hline $\begin{array}{l}\text { LDL } \\
\text { cholesterol }\end{array}$ & $\begin{array}{c}3.19 \\
(0.80) \\
\end{array}$ & 420 & $\begin{array}{c}3.54 \\
(0.87) \\
\end{array}$ & 433 & $\begin{array}{c}3.36 \\
(0.86) \\
\end{array}$ & 853 & $<.001$ \\
\hline Apo A1 & $\begin{array}{l}1500 \\
(253) \\
\end{array}$ & 417 & $\begin{array}{l}1365 \\
(199)\end{array}$ & 445 & $\begin{array}{l}1431 \\
(236)\end{array}$ & 862 & $<.001$ \\
\hline Apo B & $\begin{array}{l}914 \\
(215)\end{array}$ & 417 & $\begin{array}{l}1034 \\
(231)\end{array}$ & 445 & $\begin{array}{c}976 \\
(231)\end{array}$ & 862 & $<.001$ \\
\hline
\end{tabular}

Estimates are mean (standard deviation) if not noted otherwise.

${ }^{1}$ Comparison between women and men; $\chi^{2}$ test or $t$ test.

${ }^{2}$ Descriptive statistics based on untransformed concentrations

For consistency, we chose the more parsimonious cumulative risk formulation to represent life course SES throughout the analyses.

As our main analyses, associations between dyslipidemia and birth weight, cumulative socioeconomic disadvantage and adversity and current health behavior, were first examined by means of logistic regression analysis; results are presented as crude and adjusted Odds Ratios $(\mathrm{OR})$ and $95 \%$ confidence intervals (CI). This general approach was then extended to specific examinations of the serum levels of each lipid. For these analyses, hierarchical linear regression was used, with continuous lipid measures at age 43 regressed on birth weight (Model 1), with the subsequent addition of cumulative socioeconomic disadvantage and adversity (Model 2), and current health behavior (Model 3). Additional contribution provided by each step was appraised by the $\Delta \mathrm{R}^{2}$ with corresponding $\mathrm{F}$ test. A higher $\Delta \mathrm{R}^{2}$ provided by the first step than in the second step would indicate that birth weight plays an important role for adult lipids while life course exposures are of less importance. The reverse situation would point to life course exposures being of larger importance. Standardized regression coefficients $(\beta)$ are presented in addition to unstandardized regression coefficients (b) and standard errors (SE), to provide comparable estimates for the independent variables measured on different scales. A substantial attenuation of the birth weight coefficients with the adjustment for life course exposures could be an indication of the latter acting as confounders or mediators. Attenuation of life course coefficients in the third step would indicate that the association might be explained by behavioral pathways. Since adult BMI could act as a mediator or a confounder of birth weight [13] as well as of life course circumstances [41], in a complementary final model adjustment was done for BMI at age 43 .

Analyzes were conducted on the whole sample as well as on women and men separately. SPSS version 17.0 was used for all analyses.

\section{Results}

Dyslipidemia, birth weight and life course exposures

As can be seen in Table 2, birth weight was not related to dyslipidemia at age 43. Cumulative socioeconomic disadvantage and adversity were both positively related to dyslipidemia in the total sample. These associations seemed to be driven by results in women, while in men neither variable were related to dyslipidemia. The individual ORs were attenuated below significance by mutual

Table 2 Summary of logistic regression analyses with dyslipidemia on birth weight, cumulative socioeconomic disadvantage and cumulative adversity

\begin{tabular}{lccc}
\hline Predictor & Model $\mathbf{1}$ & Model $\mathbf{2}$ & Model $\mathbf{3}$ \\
\hline & OR (95\% Cl) & OR (95\% Cl) & OR (95\% Cl) \\
\hline Total sample & & & \\
\hline Birth weight & $1.01(0.80-1.28)$ & $0.99(0.77-1.27)$ & $1.00(0.78-1.28)$ \\
\hline Low SES & $1.12(1.01-1.24)$ & $1.08(0.98-1.20)$ & $1.06(0.96-1.18)$ \\
\hline Adversity & $1.05(1.00-1.09)$ & $1.04(0.99-1.08)$ & $1.02(0.98-1.07)$ \\
\hline Women & & & \\
\hline Birth weight & $0.92(0.63-1.34)$ & $0.95(0.63-1.43)$ & $0.93(0.62-1.41)$ \\
\hline Low SES & $1.24(1.06-1.45)$ & $1.15(0.97-1.37)$ & $1.13(0.95-1.35)$ \\
\hline Adversity & $1.07(1.01-1.14)$ & $1.05(0.99-1.12)$ & $1.04(0.98-1.11)$ \\
\hline Men & & & \\
\hline Birth weight & $0.95(0.70-1.30)$ & $0.90(0.65-1.25)$ & $0.92(0.66-1.27)$ \\
\hline Low SES & $1.01(0.88-1.15)$ & $0.99(0.87-1.13)$ & $0.97(0.85-1.11)$ \\
\hline Adversity & $1.04(0.98-1.11)$ & $1.05(0.98-1.12)$ & $1.03(0.96-1.10)$ \\
\hline
\end{tabular}

Model 1 = Bivariate (crude ORs) Model 2 = Birth weight, SES and adversity, Model $3=$ Model $2+$ health behavior (smoking, snuff use, high alcohol consumption; estimates not shown). 
adjustment, and further attenuated by the addition of health behavior.

Serum lipid levels, birth weight and life course exposures As an initial examination of linear relationships between the exposures and the lipid levels, bivariate correlations between the continuous variables of interest are shown in Table 3. As can be seen in the table, birth weight was only weakly associated with most of the outcomes, with the exception for triglycerides in women which showed a negative association with birth weight. The life course exposures (cumulative low SES and adversity) mainly seemed to be of importance for women. In women, there were also weak correlations between birth weight and the life course exposures.

These bivariate analyses were extended to hierarchical linear regression analyses. Total cholesterol was not explained by the set of predictors to any important degree, in either women (final model R2 $=.012, \mathrm{p}=$ .584 ) or men (final model $\mathrm{R} 2=.028, \mathrm{p}=.062$; current smoking being the only significant independent variable $(\mathrm{p}=.009))$. Similarly, LDL-C was not related to any of the independent variables in women (final model $\mathrm{R} 2=$ $.020, \mathrm{p}=.246$ ) or men (final model $\mathrm{R} 2=.017, \mathrm{p}=.341$ ). Summaries of the results for the remaining outcomes are found in table 4 (total sample), table 5 (women) and table 6 (men), overall displaying mixed findings.

In the total sample (table 4), birth weight was not related to any of the outcomes. Life course exposures, however, were independently related to HDL cholesterol, TG and Apo B (p change > .05). This was mainly explained by the contribution of cumulative SES, which for the most part also contributed independently of current health behavior (model 3).

In women (Table 5), birth weight was related only to triglycerides $(\mathrm{p}=.006)$, an association which remained largely unchanged throughout the subsequent steps, suggesting an independence from both life course exposures and health behaviors. Still, life course exposures (added in model 2) contributed slightly more than did birth weight $(\Delta \mathrm{R} 2=.023$ vs .019). SES did not appear to be as important as in the total sample; instead, the contribution of life course exposures was largely explained by cumulative adversity. To verify that the effect of birth weight was independent from socioeconomic disadvantage we re-run the second model with saturated SES formulation rather than the cumulative risk formulation (data not shown), resulting in no attenuation of the birth weight coefficient $(\mathrm{b}(\mathrm{SE})=-0.013(0.05), \mathrm{p}=.015)$. Similar contributions by life course exposures and adversity were apparent for HDL-C and Apo B, although slightly weaker and non-significant for Apo A1. These associations were somewhat attenuated by the addition of health behavior, indicating that the contribution by adversity was partly mediated by behavioral pathways.

In men (Table 6), associations were overall weaker and did not reach statistical significance, and life course exposures were non-significant. Birth weight displayed borderline significant relationships with HDL-C and Apo A1, independently of life course exposures and health behavior.

In complementary analyses, BMI at age 43 was added to the final model (Model 3) for each of the lipid outcomes (data not shown). BMI displayed a significant independent association with all lipids (all $\mathrm{p}<.001$ except for total cholesterol: $\mathrm{p}=.006$ ) in the total sample, and with all lipids $(\mathrm{p}<.001)$ except for total cholesterol ( $\mathrm{p}>.10$ in both women and men) and LDL-C in men $(\mathrm{p}>.10)$ in the sex-stratified analyses. The contribution of SES in the total sample was substantially attenuated by the addition of BMI, for HDL-C $(\beta=-.07$, $\mathrm{p}=.036)$, triglycerides $(\beta=.03, \mathrm{p}=.345)$ Apo $\mathrm{A} 1(\beta=$ $-.02, \mathrm{p}=.600)$ and Apo $\mathrm{B}(\beta=.02, \mathrm{p}=.580)$. In women the significant/borderline significant independent

Table 3 Zero-order correlations between the main variables, in women (below diagonal) and men (above diagonal)

\begin{tabular}{|c|c|c|c|c|c|c|c|c|c|c|c|c|}
\hline Variable & 1. & 2. & 3. & 4. & 5. & 6. & 7. & 8. & 9. & 10. & 11. & 12. \\
\hline 1. Birth weight & - & -.02 & .03 & $.08^{t}$ & .03 & -.03 & .08 & -.03 & $.09^{t}$ & $.08^{t}$ & $.09^{t}$ & .03 \\
\hline 2. LOW SES & $-.09^{t}$ & - & $.18^{* * *}$ & .07 & $.15^{* * *}$ & $.14^{* *}$ & -.01 & .07 & -.07 & -.02 & -.02 & .04 \\
\hline 3. Adversity & $-.11 *$ & $.38^{* * *}$ & - & $.09^{t}$ & $.22^{* * *}$ & $.08^{t}$ & .00 & $.08^{t}$ & .02 & -.01 & .01 & .05 \\
\hline 4. Alcohol & .03 & -.02 & .02 & - & $.11^{*}$ & .04 & $.09^{t}$ & $.13^{* *}$ & .04 & .06 & .06 & $.11^{*}$ \\
\hline 5. Smoking & -.01 & $.24^{* * *}$ & $.26^{* * *}$ & $.09^{t}$ & - & $.21^{* * *}$ & $.13^{* *}$ & $.18^{* * *}$ & -.04 & .07 & -.01 & $.19^{* * *}$ \\
\hline 6. Snuff & .01 & .08 & .07 & .07 & .02 & - & .02 & $.11^{*}$ & .02 & -.02 & .01 & .02 \\
\hline 7. Total cholesterol & $-.08^{t}$ & .01 & .05 & .01 & .06 & .05 & - & $.41^{* * *}$ & -.03 & $.94 * * *$ & $.11^{*}$ & $.90^{* * *}$ \\
\hline 8. Triglycerides & $-.15^{* *}$ & $.11^{*}$ & $.17^{* * *}$ & .00 & $.15^{* *}$ & .02 & $.44^{* * *}$ & - & $-.38^{* * *}$ & $.23^{* * *}$ & $-.24^{* * *}$ & $.55^{* * *}$ \\
\hline 9. HDL cholesterol & .04 & $-.14^{* *}$ & $-.15^{* *}$ & $.13^{* *}$ & $-.12^{*}$ & .06 & $.17^{* * *}$ & $-.31^{* * *}$ & - & $-.14^{*}$ & $-.88^{* * *}$ & $-.26^{* *}$ \\
\hline 10. LDL cholesterol & -.05 & .05 & $.08^{t}$ & -.04 & $.09^{t}$ & .03 & $.91^{* * *}$ & $.34^{* * *}$ & $-.14^{* *}$ & - & -.06 & $.87^{* * * *}$ \\
\hline 11. Apo A1 & -.02 & -.07 & $-.11^{*}$ & $.13^{* *}$ & -.07 & .09 & $.27^{* * *}$ & -.06 & $.83^{* * *}$ & -.05 & - & $-.12^{*}$ \\
\hline 12. Apo B & $-.09^{t}$ & .08 & $.14^{* *}$ & -.04 & $.16^{* *}$ & .06 & $.85^{* * *}$ & $.58^{* * *}$ & $-.22^{* * *}$ & $.87^{* * *}$ & -.01 & - \\
\hline
\end{tabular}


Table 4 Summary of hierarchical regression models in the total sample: serum lipids on birth weight in model 1, adding life course exposures (cumulative socioeconomic disadvantage (SES) and cumulative adversity) in model 2 , and current health behavior (smoking, snuff use, high alcohol consumption; estimates not shown) in model 3

\begin{tabular}{|c|c|c|c|c|c|c|c|c|c|c|}
\hline \multirow[t]{2}{*}{$\begin{array}{l}\text { Criterion } \\
\text { Predictor }\end{array}$} & \multicolumn{3}{|c|}{ Model $1=$ birth weight } & \multicolumn{3}{|c|}{$\begin{array}{c}\text { Model } 2=+ \text { life course } \\
\text { exposures }\end{array}$} & \multicolumn{4}{|c|}{ Model $3=+$ current health behavior } \\
\hline & $\Delta \mathrm{R} 2(\mathrm{p})$ & b (SE) & $\beta(p)$ & $\Delta R 2(p)$ & b (SE) & $\beta(p)$ & $\Delta R 2(p)$ & b (SE) & $\beta(p))$ & Final R2 (p) \\
\hline HDL-C & $.000(.907)$ & & & $.018(.001)$ & & & $.004(.318)$ & & & $.023(.005)$ \\
\hline Birthweight & & $0.00(0.02)$ & $.00(.907)$ & & $0.00(0.02)$ & $.00(.977)$ & & $-0.00(0.02)$ & $-.00(.963)$ & \\
\hline SES & & & & & $-0.04(0.01)$ & $\begin{array}{c}-. .14 \\
(<.001)\end{array}$ & & $-0.04(0.01)$ & $-.13(<.001)$ & \\
\hline Adversity & & & & & $0.00(0.00)$ & $.03(.449)$ & & $0.00(0.00)$ & $.03(.374)$ & \\
\hline TG & $.000(.574)$ & & & $.016(.002)$ & & & $\begin{array}{c}.027 \\
(<.001)\end{array}$ & & & $\begin{array}{c}.043 \\
(<.001)\end{array}$ \\
\hline Birthweight & & $-0.02(0.04)$ & $-.02(.574)$ & & $-0.01(0.04)$ & $-.01(.708)$ & & $-0.02(0.04)$ & $-.02(.640)$ & \\
\hline SES & & & & & $0.05(0.02)$ & $.11(.002)$ & & $0.04(0.02)$ & $.09(.013)$ & \\
\hline Adversity & & & & & $0.01(0.01)$ & $.04(.322)$ & & $0.00(0.01)$ & $.01(.751)$ & \\
\hline Apo A1 & $.000(.988)$ & & & $.005(.154)$ & & & $.004(.324)$ & & & $.009(.301)$ \\
\hline Birthweight & & $-0.22(14.8)$ & $.00(.988)$ & & $-1.47(14.8)$ & $-.00(.921)$ & & $-2.91(14.8)$ & $-.01(.844)$ & \\
\hline SES & & & & & $-11.3(6.18)$ & $-.07(.068)$ & & $-11.5(6.25)$ & $-.07(.067)$ & \\
\hline Adversity & & & & & $-0.52(2.61)$ & $-.01(.844)$ & & $-0.53(2.67)$ & $-.007(.842)$ & \\
\hline Apo B & $.000(.676)$ & & & $.009(.030)$ & & & $.019(.001)$ & & & $.028(.001)$ \\
\hline Birthweight & & $6.01(14.4)$ & $.02(.676)$ & & 8.19 (14.4) & $.02(.568)$ & & $7.91(14.3)$ & $.02(.579)$ & \\
\hline SES & & & & & $13.2(5.99)$ & $.08(.028)$ & & $9.76(6.02)$ & $.06(.105)$ & \\
\hline Adversity & & & & & $2.40(2.54)$ & $.03(.346)$ & & $0.40(2.58)$ & $.01(.878)$ & \\
\hline
\end{tabular}

contributions of adversity were unaffected by the addition of BMI for all lipids, as was the contribution of birth weight for triglycerides $(\beta=.11, \mathrm{p}=.018)$. In men, the near-significant contributions of birth weight were slightly accentuated and reached significance for both $\operatorname{HDL}-\mathrm{C}(\beta=10, \mathrm{p}=.030)$ and Apo A1 $(\beta=.10 \mathrm{p}=$ $.041)$. There were no other substantial changes of coefficients.

\section{Discussion}

This study provides support for the hypothesis that the accumulation of unfavorable circumstances over the life course is related to adult dyslipidemia. Similar results were shown for serum levels of some lipids (HDL-C, triglycerides, Apo B) but not others (Total cholesterol, LDL-C, Apo A1). Associations were mainly found among women. Support for the fetal origins hypothesis was only found for triglycerides in women. Thus, life course exposures provided a more substantial overall contribution to adult serum lipids than did birth weight.

In the total sample, birth weight was not related to dyslipidemia or to any specific lipids, while cumulative socioeconomic disadvantage displayed significant associations with dyslipidemia, HDL-C, triglycerides and Apo B. For dyslipidemia, the independent contribution of SES and adversity were nonsignificant after mutual adjustment, possibly due their interrelationship, and the
ORs were further attenuated by the addition of health behaviors. For HDL-C and triglycerides these associations seemed to be independent of current health behavior. These results support previous indications of weak and inconsistent influences of birth weight on lipids [13], and generally give support for the abundance of findings showing cumulative SES to be of importance for cardiovascular health [18].

The separate analyses on women and men provided a partly different picture. In women, triglycerides were significantly related to birth weight, an association independent of both social and behavioral factors. This is in line with previous findings indicating triglycerides to be the lipids with the most consistent association to birth weight [13], although similar results were not found in men. It has been suggested that since triglycerides are related to insulin, this lipid could indicate an aspect of extensive metabolic disorder including insulin resistance, and that this could be a reason as to why triglycerides are the lipids which show the most consistent association to birth weight [13]. It should be noted though, that even for triglycerides the contribution of life course exposures exceeded that of birth weight. This life course contribution was mainly explained by cumulative adversity, which also was the most important life course factor for the other lipid outcomes in women. However, although the independent contribution of SES was only 
Table 5 Summary of hierarchical regression models in women: serum lipids on birth weight in model 1, adding life course exposures (cumulative socioeconomic disadvantage (SES) and cumulative adversity) in model 2 , and current health behavior (smoking, snuff use, high alcohol consumption; estimates not shown) in model 3

\begin{tabular}{|c|c|c|c|c|c|c|c|c|c|c|}
\hline \multirow{2}{*}{$\begin{array}{l}\text { Criterion } \\
\quad \text { Predictor }\end{array}$} & \multicolumn{3}{|c|}{ Model $1=$ birth weight } & \multicolumn{3}{|c|}{ Model $2=+$ life course exposures } & \multicolumn{4}{|c|}{ Model $3=+$ current health behavior } \\
\hline & $\Delta R 2(p)$ & b (SE) & $\beta(p)$ & $\Delta R 2(p)$ & b (SE) & $\beta(p)$ & $\Delta R 2(p)$ & b (SE) & $\beta(p))$ & Final R2 (p) \\
\hline $\mathrm{HDL}-\mathrm{C}$ & $.003(.296)$ & & & $.029(.006)$ & & & $.032(.005)$ & & & $.061(<.001)$ \\
\hline Birthweight & & $0.04(0.04)$ & $.05(.296)$ & & $0.02(0.04)$ & $.03(.544)$ & & $0.02(0.04)$ & $.03(.504)$ & \\
\hline SES & & & & & $-0.03(0.02)$ & $-.09(.092)$ & & $-0.02(0.02)$ & $-.08(.129)$ & \\
\hline Adversity & & & & & $-0.01(0.01)$ & $-.11(.049)$ & & $-0.01(0.01)$ & $-.10(.068)$ & \\
\hline TG & $.019(.006)$ & & & $.023(.010)$ & & & $.010(.241)$ & & & $.053(.002)$ \\
\hline Birthweight & & $-0.14(0.05)$ & $-.14(.006)$ & & $-0.12(0.05)$ & $-.12(.019)$ & & $-0.12(0.05)$ & $-.12(.016)$ & \\
\hline SES & & & & & $0.02(0.02)$ & $.05(.395)$ & & $0.01(0.02)$ & $.03(.555)$ & \\
\hline Adversity & & & & & $0.02(0.01)$ & $.13(.015)$ & & $0.02(0.01)$ & $.11(.047)$ & \\
\hline Apo A1 & $.000(.883)$ & & & $.012(.100)$ & & & $.033(.005)$ & & & $.045(.007)$ \\
\hline Birthweight & & $-3.62(24.6)$ & $-.01(.883)$ & & $-10.9(24.8)$ & $-.02(.660)$ & & $-10.4(24.5)$ & $-.02(.671)$ & \\
\hline SES & & & & & $-5.44(10.5)$ & $-.03(.604)$ & & $-4.58(10.5)$ & $-.02(.662)$ & \\
\hline Adversity & & & & & $-7.04(3.97)$ & $-.010(.077)$ & & $-7.20(4.01)$ & $-.10(.074)$ & \\
\hline Apo B & $.006(.122)$ & & & $.020(.020)$ & & & $.022(.033)$ & & & $.048(.004)$ \\
\hline Birthweight & & $-32.3(20.9)$ & $-.08(.122)$ & & $-24.3(20.9)$ & $-.06(.246)$ & & $-26.5(20.8)$ & $-.06(.203)$ & \\
\hline SES & & & & & $6.46(8.83)$ & $.04(.465)$ & & 3.03 (8.86) & $.02(.733)$ & \\
\hline Adversity & & & & & $7.64(3.35)$ & $.12(.023)$ & & 5.88(3.39) & $.01(.084)$ & \\
\hline
\end{tabular}

near-significant, it should be noted that SES was related to HDL-C cholesterol and triglycerides in the bivariate analyses (Table 3). This association was attenuated when SES and adversity were simultaneously included in the model, probably as a consequence of the association between these two exposures $(r=.38$, Table 3$)$. This pattern in women differed from that in men, where both birth weight and life course exposures displayed only weak associations with lipids and the strongest associations were found with health behaviors. Other studies have found social exposures over the life course to be of greater important for women than men

Table 6 Summary of hierarchical regression models in men: serum lipids on birth weight in model 1, adding life course exposures (cumulative socioeconomic disadvantage (SES) and cumulative adversity) in model 2 , and current health behavior (smoking, snuff use, high alcohol consumption; estimates not shown) in model 3

\begin{tabular}{|c|c|c|c|c|c|c|c|c|c|c|}
\hline \multirow{2}{*}{$\begin{array}{l}\text { Criterion } \\
\text { Predictor }\end{array}$} & \multicolumn{3}{|c|}{ Model 1 = birth weight } & \multicolumn{3}{|c|}{ Model $2=+$ life course exposures } & \multicolumn{4}{|c|}{ Model $3=+$ current health behavior } \\
\hline & $\Delta R 2(p)$ & b (SE) & $\beta(p)$ & $\Delta R 2(p)$ & b (SE) & $\beta(p)$ & $\Delta R 2(p)$ & b (SE) & $\beta(p))$ & Final R2 (p) \\
\hline $\mathrm{HDL}-\mathrm{C}$ & $.008(.070)$ & & & $.007(.249)$ & & & $.007(.419)$ & & & $.021(.180)$ \\
\hline Birthweight & & $0.05(0.03)$ & $.09(.070)$ & & $0.05(0.03)$ & $.09(.077)$ & & $0.05(0.03)$ & $.09(.083)$ & \\
\hline SES & & & & & $-0.02(0.01)$ & $-.08(.109)$ & & $-0.02(0.01)$ & $-.08(.104)$ & \\
\hline Adversity & & & & & $0.00(0.01)$ & $.034(.487)$ & & $0.00(0.01)$ & $.041(.411)$ & \\
\hline TG & $.001(.583)$ & & & $.012(.074)$ & & & $.040(.001)$ & & & $.053(.001)$ \\
\hline Birthweight & & $-0.03(0.05)$ & $-.03(.583)$ & & $-0.03(0.05)$ & $-.03(.582)$ & & $-0.03(0.05)$ & $-.03(.556)$ & \\
\hline SES & & & & & $0.03(0.02)$ & $.08(.117)$ & & $0.02(0.02)$ & $.05(.279)$ & \\
\hline Adversity & & & & & $0.02(0.01)$ & $.07(.160)$ & & $0.01(0.01)$ & $.03(.528)$ & \\
\hline Apo A1 & $.009(.061)$ & & & $.000(.926)$ & & & $.003(.780)$ & & & $.012(.577)$ \\
\hline Birthweight & & $30.7(16.3)$ & $.09(.061)$ & & $30.6(16.4)$ & $.09(.063)$ & & $30.3(16.5)$ & $.09(.067)$ & \\
\hline SES & & & & & $-2.62(6.80)$ & $-.02(.700)$ & & $-3.25(6.89)$ & $-.02(638)$ & \\
\hline Adversity & & & & & $-0.05(3.23)$ & $0.00(.989)$ & & $-0.12(3.31)$ & $-.00(.971)$ & \\
\hline Apo B & $.001(.625)$ & & & $.002(.612)$ & & & $.040(.001)$ & & & $.043(.004)$ \\
\hline Birthweight & & $9.26(18.9)$ & $.02(.625)$ & & $9.44(19.0)$ & $.03(.619)$ & & 7.92 (18.7) & $.02(.673)$ & \\
\hline SES & & & & & $6.30(7.88)$ & $.04(.424)$ & & $3.66(7.83)$ & $.02(.640)$ & \\
\hline Adversity & & & & & $1.73(3.75)$ & $.02(.645)$ & & $-1.13(3.76)$ & $-.02(.763)$ & \\
\hline
\end{tabular}


$[23,24,42,43]$. This might be explained by structural patterns of unfavorable life circumstances which women are at greater risk for than men, in the present study supported by the substantially larger amount of adversities experienced by women than men (Table 1).

Adult BMI strongly attenuated the contribution of SES in the total sample, consistent with BMI acting as a mediator in the SES-lipids relationship. In men, the contribution of birth weight was slightly accentuated after the addition of BMI in adulthood, a phenomenon that has been highlighted in the literature on association between birth weight and lipids [13] and blood pressure [8]. Possibly, this could be explained by the contrasting effects of birth weight: birth weight is inversely associated with adult lipids, but positively associated with adult body mass, which in turn is positively related to lipids.

Total cholesterol and LDL cholesterol displayed no association with either birth weight or life course exposures. This is consistent with the observations that birth weight is only insubstantially related to total cholesterol levels [14]. Moreover, socioeconomic influences on total and LDL cholesterol are inconsistently reported in the literature [44].

\section{Methodological considerations}

The main strengths of this study are the prospective design and high response rate. The high response rate, achieved despite the long-term prospective design, protects against selection bias which otherwise could influence the results [45]. In addition, missing data on the outcome measures, the chief source of internal drop-out, did not appear to be systematic with respect to any of the studied exposures. Assessment of birth weight based on birth records, as was done in this study, is preferable to self-reported retrospective recall, since the latter might be confounded by factors such as socioeconomic status or age at the time of reporting $[46,47]$. Also, a large part of the respondents might not be able to provide self-reports, which might introduce systematic error [46]. Error in self-report also tend to produce attenuation of observed associations [47]. Similarly, adult retrospective reports of adverse childhood experiences generally involve a large fraction of false negative responses and a considerable measurement error [48], which is why the prospective approach of the present study is preferable. These measurement issues are especially important in a study aiming at estimating the relative contribution of different exposures. Social deprivation has been shown to be related to birth weight [49], but there are also some reports of independent associations between birth weight and social circumstances later in life, e.g., unemployment in both women and men [50]. However, this association seems to be of less importance than social disadvantage in childhood [50].
The simple dichotomization of socioeconomic status at each age could possibly mask variation of SES important for the studied outcomes. However, this approach is a conventional operationalization of the cumulative risk model [51,52]. Although other conceptual life course models could have been examined, the cumulative risk model is the model that has received most support in the literature [18]. Our index of cumulative adversity differs from cumulative SES since it consists of exposures of widely different qualities, e.g. regarding the temporal demarcation, degree of threat, and social context of the adversities. This span of qualities should provide a reasonably comprehensive assessment of social adversities during the life course, although we do not have information on some salient exposures, e.g. particularly traumatic events in childhood, which might be of importance for adult health [53]. The simple number of adversities has been shown to be a practical way of summarizing total adversity exposure in relation to the health of children [54,55] and adults [21,56,57]. Nevertheless, our cumulative adversity measure is a crude operationalization and does not consider specific effects of individual adversities and timing of effects; such issues would be expected to confer a loss of power. Moreover, the lack of information on social circumstances during early childhood is a limitation of the study.

The meager findings concerning birth weight could be a result of too small a sample size and insufficient power. However, the aim of the study was to examine the relative contributions of different classes of exposures, and despite mainly non-significant results regarding birth weight, both life course exposures and health behaviors displayed more consistent associations with the outcomes. Thus, the relatively lower explanatory value of birth weight compared to life course exposures can still be interpreted. As noted, these findings are in line with previous research concluding that although there might be an influence of birth weight on adult cardiovascular risk factors, it is dubious that this potential effect is of substantial practical importance in this area $[8,14]$.

\section{Conclusions}

The accumulation of adverse social circumstances over the life course was found to be of relevance for dyslipidemia and serum levels of some lipids in adulthood, while the contributions of birth weight were inconsistent and where present, eclipsed by the stronger contribution of accumulated life course exposures. These results indicates that although there might be a weak influence of fetal conditions, social conditions and experiences over the life course do play a greater role for cardiovascular risk factors in adulthood. 


\section{Acknowledgements}

Data collection at age 43 was funded by The Swedish Research Council and by The Swedish Council for Working Life and Social Research. The funding bodies had no role in study design; in collection, analysis or interpretation of the data; or in writing or submission of the manuscript. We also wish to express our gratitude to all the participants in the study.

\section{Author details}

Dept of Public Health and Clinical Medicine, Family Medicine, Umeå University, Umeå, Sweden. ${ }^{2}$ Dept of Public Health and Clinical Medicine, Epidemiology and Global Health, Umeå University, Umeå, Sweden. ${ }^{3}$ Stress Research Institute, Stockholm University, Stockholm, Sweden.

\section{Authors' contributions}

AH was responsible for the conception and design of the study and $\mathrm{UJ}$ and $\Pi$ contributed to the design of the study. $\mathrm{AH}$ and $\mathrm{UJ}$ were responsible for the data collection. PEG was responsible for the statistical analyses and writing the first draft of the manuscript. All authors participated in interpreting the results, provided input on manuscript drafts, and read and approved the final manuscript.

\section{Competing interests}

The authors declare that they have no competing interests.

Received: 24 March 2010 Accepted: 16 August 2010

Published: 16 August 2010

\section{References}

1. Kuh D, Ben-Shlomo Y, Lynch J, Hallqvist J, Power C: Life course epidemiology. J Epidemiol Community Health 2003, 57:778-783.

2. Barker DJ, Fall CH: Fetal and infant origins of cardiovascular disease. Arch Dis Child 1993, 68:797-799.

3. Leon DA, Lithell HO, Vagero D, Koupilova I, Mohsen R, Berglund L, Lithell UB, McKeigue PM: Reduced fetal growth rate and increased risk of death from ischaemic heart disease: cohort study of 15 000Swedish men and women born 1915-29. BMJ 1998, 317:241-245.

4. Barker DJ, Winter PD, Osmond C, Margetts B, Simmonds SJ: Weight in infancy and death from ischaemic heart disease. Lancet 1989, 2:577-580.

5. Curhan GC, Willett WC, Rimm EB, Spiegelman D, Ascherio AL, Stampfer MJ: Birth weight and adult hypertension, diabetes mellitus, and obesity in US men. Circulation 1996, 94:3246-3250.

6. Curhan GC, Chertow GM, Willett WC, Spiegelman D, Colditz GA, Manson JE, Speizer FE, Stampfer MJ: Birth weight and adult hypertension and obesity in women. Circulation 1996, 94:1310-1315.

7. Grunnet L, Vielwerth S, Vaag A, Poulsen P: Birth weight is nongenetically associated with glucose intolerance in elderly twins, independent of adult obesity. J Intern Med 2007, 262:96-103.

8. Huxley R, Neil A, Collins R: Unravelling the fetal origins hypothesis: is there really an inverse association between birthweight and subsequent blood pressure? Lancet 2002, 360:659-665.

9. Gillman MW: Epidemiological challenges in studying the fetal origins of adult chronic disease. Int J Epidemiol 2002, 31:294-299.

10. Fall CH, Barker DJ, Osmond C, Winter PD, Clark PM, Hales CN: Relation of infant feeding to adult serum cholesterol concentration and death from ischaemic heart disease. BMJ 1992, 304:801-805.

11. Barker DJ, Martyn CN, Osmond C, Hales CN, Fall CH: Growth in utero and serum cholesterol concentrations in adult life. BMJ 1993, 307:1524-1527.

12. Fall CH, Osmond C, Barker DJ, Clark PM, Hales CN, Stirling Y, Meade TW: Fetal and infant growth and cardiovascular risk factors in women. BMJ 1995, 310:428-432

13. Lauren $L$, Jarvelin MR, Elliott $P$, Sovio $U$, Spellman A, McCarthy $M$, Emmett $P$, Rogers I, Hartikainen AL, Pouta A, et al: Relationship between birthweight and blood lipid concentrations in later life: evidence from the existing literature. Int J Epidemiol 2003, 32:862-876.

14. Huxley R, Owen CG, Whincup PH, Cook DG, Colman S, Collins R: Birth weight and subsequent cholesterol levels: exploration of the "fetal origins" hypothesis. JAMA 2004, 292:2755-2764.

15. Radunovic N, Kuczynski E, Rosen T, Dukanac J, Petkovic S, Lockwood CJ: Plasma apolipoprotein $\mathrm{A}-\mathrm{I}$ and $\mathrm{B}$ concentrations in growth-retarded fetuses: a link between low birth weight and adult atherosclerosis. J Clin Endocrinol Metab 2000, 85:85-88.
16. Kajantie E, Barker DJ, Osmond C, Forsen T, Eriksson JG: Growth before 2 years of age and serum lipids 60 years later: the Helsinki Birth Cohort study. Int J Epidemiol 2008, 37:280-289.

17. Robinson SM, Batelaan SF, Syddall HE, Sayer AA, Dennison EM, Martin HJ, Barker DJ, Cooper C: Combined effects of dietary fat and birth weight on serum cholesterol concentrations: the Hertfordshire Cohort Study. Am J Clin Nutr 2006, 84:237-244.

18. Pollitt RA, Rose KM, Kaufman JS: Evaluating the evidence for models of life course socioeconomic factors and cardiovascular outcomes: a systematic review. BMC Public Health 2005, 5:7.

19. Naess O, Claussen B, Thelle DS, Davey Smith G: Cumulative deprivation and cause specific mortality. A census based study of life course influences over three decades. J Epidemiol Community Health 2004, 58:599-603.

20. Lynch JW, Kaplan GA, Shema SJ: Cumulative impact of sustained economic hardship on physical, cognitive, psychological, and social functioning. N Engl J Med 1997, 337:1889-1895.

21. Schilling EA, Aseltine RH, Gore S: The impact of cumulative childhood adversity on young adult mental health: measures, models, and interpretations. Soc Sci Med 2008, 66:1140-1151.

22. Lehman BJ, Taylor SE, Kiefe Cl, Seeman TE: Relation of childhood socioeconomic status and family environment to adult metabolic functioning in the CARDIA study. Psychosom Med 2005, 67:846-854

23. Brunner E, Shipley MJ, Blane D, Smith GD, Marmot MG: When does cardiovascular risk start? Past and present socioeconomic circumstances and risk factors in adulthood. J Epidemiol Community Health 1999, 53:757-764.

24. Power C, Atherton K, Strachan DP, Shepherd P, Fuller E, Davis A, Gibb I, Kumari M, Lowe G, Macfarlane GJ, et al: Life-course influences on health in British adults: effects of socio-economic position in childhood and adulthood. Int J Epidemiol 2007, 36:532-539.

25. Davies AA, Smith GD, Ben-Shlomo Y, Litchfield P: Low birth weight is associated with higher adult total cholesterol concentration in men: findings from an occupational cohort of 25,843 employees. Circulation 2004, 110:1258-1262.

26. Hammarström A: Youth unemployment and ill-health. results from a two year follow-up study. (in Swedish, summary in English). Doctoral thesis, monograph Karolinska Institute 1986.

27. Hammarstrom A, Janlert U: Health selection in a 14-year follow-up studya question of gendered discrimination? Soc Sci Med 2005, 61:2221-2232.

28. Thorlsund M, Wärneryd B: Methodological Research in the Swedish Surveys of Living Conditions. Problems of Meassurement and Data Collection. Social Indicators Research 1985, 16:77-95.

29. Johansson S: The adult population's state of health [in Swedish] Stockholm: Fritzes 1970

30. Sverige. Medicinalstyrelsen: Klassifikation av sjukdomar: International statistical classification of diseases, injuries and causes of death: 1955 revision adapted for indexing of hospital records and morbidity statistics Stockholm: Nord Bokh, 61964

31. Aberg Yngwe M, Lundberg O, Burstrom B: On the importance of internalized consumption norms for ill health. Scand J Public Health 2006, 34:76-82.

32. Orth-Gomer K, Unden AL: The measurement of social support in population surveys. Soc Sci Med 1987, 24:83-94.

33. Henderson S, Duncan-Jones P, Byrne DG, Scott R: Measuring social relationships. The Interview Schedule for Social Interaction. Psychol Med 1980, 10:723-734.

34. Karasek R, Theorell T: Healthy work: stress, productivity, and the reconstruction of working life New York, N.Y.: Basic Books 1990.

35. Statistics Sweden: Swedish socioeconomic classification. Reports on statistical co-ordination 1982:4. Stockholm 1984.

36. Rydberg U, Damström Thakker K, Skerfving S: Risk Evaluation of Alcohol. International Review of Psychiatry Washington: American Psychiatric PressCosta e Silva JA, Nadelson CC 1993, 1:563-600.

37. World Health Organization. Cardiovascular Diseases Unit: MONICA manual: WHO MONICA project Geneva: World Health Organization 1990.

38. Guidelines Committee: 2003 European Society of Hypertension-European Society of Cardiology guidelines for the management of arterial hypertension. J Hypertens 2003, 21:1011-1053.

39. Mancia G, De Backer G, Dominiczak A, Cifkova R, Fagard R, Germano G, Grassi G, Heagerty AM, Kjeldsen SE, Laurent S, et al: 2007 Guidelines for 
the Management of Arterial Hypertension: The Task Force for the Management of Arterial Hypertension of the European Society of Hypertension (ESH) and of the European Society of Cardiology (ESC). $J$ Hypertens 2007, 25:1105-1187.

40. Mishra G, Nitsch D, Black S, De Stavola B, Kuh D, Hardy R: A structured approach to modelling the effects of binary exposure variables over the life course. Int J Epidemiol 2009, 38:528-537.

41. Senese LC, Almeida ND, Fath AK, Smith BT, Loucks EB: Associations between childhood socioeconomic position and adulthood obesity. Epidemiol Rev 2009, 31:21-51.

42. Santos AC, Ebrahim S, Barros H: Gender, socio-economic status and metabolic syndrome in middle-aged and old adults. BMC Public Health 2008, 8:62.

43. Ahnquist J, Fredlund $P$, Wamala SP: Is cumulative exposure to economic hardships more hazardous to women's health than men's? A 16-year follow-up study of the Swedish Survey of Living Conditions. J Epidemiol Community Health 2007, 61:331-336

44. Perova NV, Davis CE, Tao S, Pajak A, Stein Y, Broda GB, Li Y, Tyroler HA: Multi-country comparison of plasma lipid relationship to years of schooling in men and women. Int J Epidemiol 2001, 30:371-379.

45. Novo M, Hammarstrom A, Janlert U: Does low willingness to respond introduce a bias? - Results from a socio-epidemiological study among young men and women. Int I Soc Welfare 1999, 8:155-163.

46. Allen DS, Ellison GT, dos Santos Silva I, De Stavola BL, Fentiman IS: Determinants of the availability and accuracy of self-reported birth weight in middle-aged and elderly women. Am J Epidemiol 2002, 155:379-384.

47. Tehranifar P, Liao Y, Flom JD, Terry MB: Validity of self-reported birth weight by adult women: sociodemographic influences and implications for life-course studies. Am J Epidemiol 2009, 170:910-917.

48. Hardt J, Rutter M: Validity of adult retrospective reports of adverse childhood experiences: review of the evidence. J Child Psychol Psychiatry 2004, 45:260-273.

49. Wilcox MA, Smith SJ, Johnson IR, Maynard PV, Chilvers CE: The effect of social deprivation on birthweight, excluding physiological and pathological effects. Br J Obstet Gynaecol 1995, 102:918-924.

50. Kristensen $P$, Bjerkedal T, Irgens LM: Birthweight and work participation in adulthood. Int J Epidemiol 2004, 33:849-856.

51. Hallqvist J, Lynch J, Bartley M, Lang T, Blane D: Can we disentangle life course processes of accumulation, critical period and social mobility? An analysis of disadvantaged socio-economic positions and myocardial infarction in the Stockholm Heart Epidemiology Program. Soc Sci Med 2004, 58:1555-1562.

52. Rosvall M, Chaix B, Lynch J, Lindstrom M, Merlo J: Similar support for three different life course socioeconomic models on predicting premature cardiovascular mortality and all-cause mortality. BMC Public Health 2006, 6:203.

53. Felitti VJ, Anda RF, Nordenberg D, Williamson DF, Spitz AM, Edwards V, Koss MP, Marks JS: Relationship of childhood abuse and household dysfunction to many of the leading causes of death in adults. The Adverse Childhood Experiences (ACE) Study. Am J Prev Med 1998, 14:245-258.

54. Bauman LJ, Silver EJ, Stein RE: Cumulative social disadvantage and child health. Pediatrics 2006, 117:1321-1328.

55. Gustafsson PE, Nilsson D, Svedin CG: Polytraumatization and psychological symptoms in children and adolescents. Eur Child Adolesc Psychiatry 2009, 18:274-283.

56. Turner RJ, Lloyd DA: Lifetime traumas and mental health: The significance of cumulative adversity. J Health Soc Behav 1995, 36:360-376.

57. Steptoe A, Marmot M: Burden of psychosocial adversity and vulnerability in middle age: associations with biobehavioral risk factors and quality of life. Psychosom Med 2003, 65:1029-1037.

\section{Pre-publication history}

The pre-publication history for this paper can be accessed here: http://www.biomedcentral.com/1471-2458/10/484/prepub

doi:10.1186/1471-2458-10-484

Cite this article as: Gustafsson et al:: Fetal and life course origins of serum lipids in mid-adulthood: results from a prospective cohort study. BMC Public Health 2010 10:484

\section{Submit your next manuscript to BioMed Central and take full advantage of:}

- Convenient online submission

- Thorough peer review

- No space constraints or color figure charges

- Immediate publication on acceptance

- Inclusion in PubMed, CAS, Scopus and Google Scholar

- Research which is freely available for redistribution 